\title{
ПРИМЕНЕНИЕ ЛИНЕАМЕНТНОГО АНАЛИЗА ДЛЯ ОЦЕНКИ КАРСТООПАСНОСТИ ПРИ ПРОЕКТИРОВАНИИ МАГИСТРАЛЬНОГО ГАЗОПРОВОДА В ЮЖНОЙ ЯКУТИИ
}

\author{
Строкова Людмила Александровна 1 , \\ sla@tpu.ru
}

\author{
Ежкова Алёна Викторовна², \\ alyona7@inbox.ru \\ Леонова Анна Владимировна1, \\ avleonova@tpu.ru \\ 1 Национальный исследовательский Томский политехнический университет, \\ Россия, 634050, г. Томск, пр. Ленина, 30. \\ 2000 «Газпром Инвест», \\ Россия, 634034, г. Томск, пр. Ленина, 39.
}

\begin{abstract}
Актуальность работы обусловлена строительством магистрального газопровода в южной Якутии. Район характеризуется сложными природно-климатическими условиями, слабой инженерно-геологической изученностью, широким развитием карстующихся пород, малой численностью населения. Учитывая недостаточность данных наблюдений за карстом, особую важность приобретает привлечение данных дистанционного зондирования территории для изучения зон повышенной трещиноватости пород, в частности линеаментный анализ. Линеамент на космоснимке - это линейно-полосчатая текстура снимка, которая на местности отражает особенности геологической структуры, такие как зоны разрывных нарушений, трещин и дробления горных пород, с которыми связана максимальная проницаемость земной коры для тепломассопереноса и миграции газовых и жидких растворов. Последнее обстоятельство открывает путь к оценке и прогнозу не только перспективности территории на наличие полезных ископаемых, но и опасности развития экзогенных геологических процессов, таких как линейной эрозии, карста, оползней. Физическая природа связи линеаментов и проявлений карста позволяет применять линеаментный анализ при оценке условий строительства сооружений на закарстованных территориях.

Цель работы: понять пространственное распределение линеаментов, их ориентацию, плотность, как фракторов, влияющих на развитие карстового процесса.

Методика. Основное внимание в исследовании уделяется вопросу извлечения линеаментов в пределах трассы магистрального газопровода с помощью цифровой модели рельефра. Линеаменты извлекались и анализировались в программах Geomatica и ArcGIS cоответственно.

Результаты. Использование современных технологий выделения линеаментов на космических снимках открывает новые возможности для изучения геологического строения территории. Составлены карты распространения линеаментов и их плотности на исследуемой области. Инсрормация по структурно-тектоническим условиям территории и полученные результаты линеаментного анализа использованы для оценки карстовой опасности района проложения трассы.
\end{abstract}

\section{Ключевые слова:}

Магистральные газопроводы, оценка риска, линеамент, геоинформационные системы, карст.

\section{Введение}

Значительная часть территории южной Якутии, где проходит трасса магистрального газопровода, характеризуется распространением карстующихся пород, при этом многолетние наблюдения за карстом отсутствуют, т. к. территория является малонаселенной. Присутствие карстующихся пород в геологическом разрезе усложняет условия строительства и эксплуатации сооружений и требует оценки степени карстовой опасности.

Одним из условий развития карста является возможность движения подземных вод. Как правило, путями движения подземных вод являются трещины, наличие которых в свою очередь зависит от тектонической обстановки территории. Указанное обстоятельство неоднократно описано разными авторами. Так, например, А.И. Печеркин, Г.Б. Болотов, В.Н. Катаев отмечают, что зоны повышенной трещиноватости, такие как своды положительных структур, их крутые крылья, приразрывные участки, имеют максимальную закарстованность [1]. При исследовании территории г. Кунгур отмечено, что с зонами повышенной трещиноватости могут быть связаны зоны локальной проницаемости карстового массива, зоны локализации стока подземных вод в условиях активного водообмена. И с учетом основного свойства массива горных пород, а именно - растворяться при контакте с недонасыщенными подземными водами, указанные зоны, могут быть активны с позиции карстообразования [2].

Для выделения зон повышенной трещиноватости перспективно проведение линеаментного анализа района. Линеаментный анализ - эффективный комплекс геоморфологических, геологических, дистанционных и других методов геологического картирования и мониторинга опасных геологических процессов. Базовыми объектами анализа являются линеаменты, вытянутые в одном направлении линейные элементы рельефа и геологической структуры. Линии 
проводят по набору диагностических признаков на геолого-геоморфологических картах, разрезах, блокдиаграммах, схемах и моделях [3]. Следует заметить, что на текущий момент не существует однозначного определения термина «линеамент», их однозначной классификации, а также, что базовые приемы изучения линеаментов в практике инженерных изысканий на закарстованных территориях связаны в отечественной карстологической практике, в основном с работами пермских карстоведов [4-6].

Для проведения линеаментного анализа в настоящее время широко используются автоматизированные методы, это объясняется достоверностью получаемых результатов, свободных от субъективных ошибок дешифрирования [7-14]. В первую очередь, это относится к анализу рисунка хребтов и долин в цифровых моделях рельефа (ЦМР). Преимущество анализа цифровой модели рельефа заключается в том, что в анализе участвуют только элементы рельефа и исключены яркостные аномалии, обусловленные другими источниками, такими как растительность и техногенные объекты.

Целью данного исследования является определение пространственного распространения линеаментов, их ориентации и плотности по трассе магистрального газопровода.

Исследование включало анализ литературных и фондовых материалов, полученных при инженерногеологических изысканиях, выполненных в 2012 г. [15], инженерно-геологическое типологическое картогра- фирование трассы, проведенное в 2016 г. в отделении геологии ТПУ [16-20]. Для выделения зон повышенной трещиноватости по данным дистанционного зондирования использовались данные, полученные при помощи космического термоэмиссионного и отражающего радиометра ASTER (Advanced Spaceborne Thermal Emission and Reflection Radiometer), отраженные в GDEM (Global Digital Elevation Model) - глобальной цифровой модели рельефа. Данные были загружены при помощи бесплатного сервиса «NASA Earthdata Search», использовалась версия цифровой модели рельефа «Aster GDEM V003». Их обработка проводилась осенью 2019 г. в отделении геологии ТПУ с помощью «ArcGIS Desktop». Учитывая, что в рельефе линеаменты выражаются закономерно ориентированными зонами, образованными прямолинейными границами горных хребтов и кряжей, берегов озер и крупных болот, спрямленными участками речных и ледниковых долин, цепочками просадок различного генезиса и т. п., анализ базируется на автоматизированном выделении таких зон по ЦМР [8-14].

Для выяснения природы линеаментов, как отражающих линейные структуры глубинного строения, использовался совместный анализ результатов обработки ЦМР и данных, полученных традиционными геолого-геофизическими методами. С этой целью результаты сопоставлялись с картами геологическими, геоморфологическими, четвертичных отложений и другими.

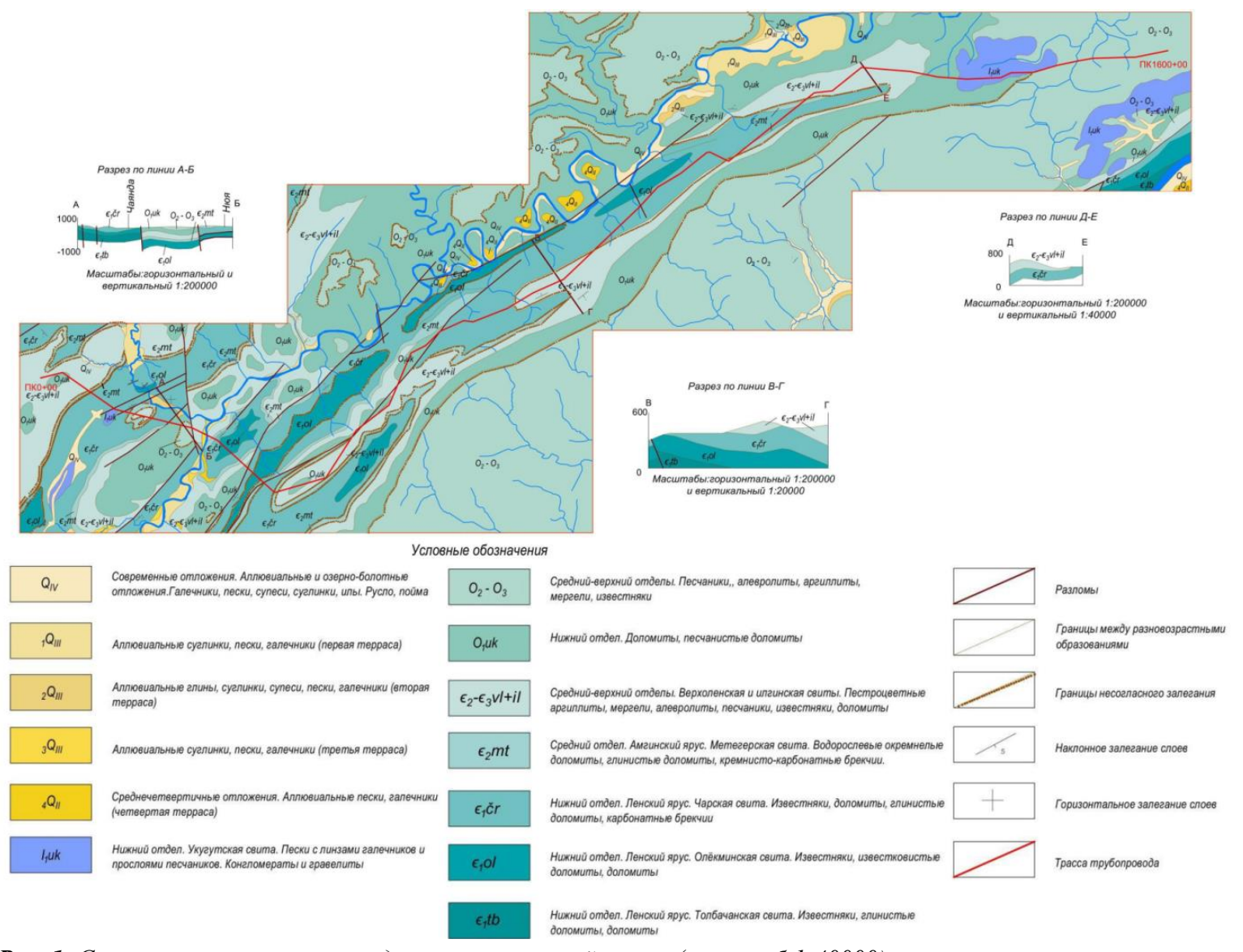

Pис. 1. Схема марирута газопровода на геологической карте (масштаб 1:40000)

Fig. 1. Gas pipeline route scheme on the geological map (at 1:40000 scale) 


\section{Характеристика природных условий территории}

Климат района резко континентальный, с характерно холодной зимой, жарким летом, незначительным количеством осадков и значительным перепадом температур в течение года. Незначительный снежный покров и исключительно низкие зимние температуры способствуют широкому распространению многолетней мерзлоты.

По орогидрографическому делению исследуемый район расположен на Приленском плато Среднесибирского плоскогорья, в бассейне левобережных притоков верхнего и среднего течения р. Лены. Детальная характеристика природных условий района трассы приведена в работах $[16,20]$.
Более подробно остановимся на описании структурно-тектонических условий района. Трасса газопровода расположена в южной части Сибирской платформы, начинается в пределах Непского свода Непско-Ботуобинской антеклизы и заканчивается в пределах Предпатомского прогиба. Территория сложена отложениями кембрия и ордовика (рис. 1), смятыми в протяженные гребневидные складки, простирающиеся в северо-восточном направлении. Складки осложнены многочисленными разрывами, преимущественно надвигами, падающими на юго-восток.

Трасса газопровода пересекает следующие основные тектонические зоны: Пеледуй-Олдонскую антиклинальную зону, Нюйскую синклинальную зону, Средненюйскую антиклинальную зону, НюйскоХамаринскую синклинальную зону (рис. 2).

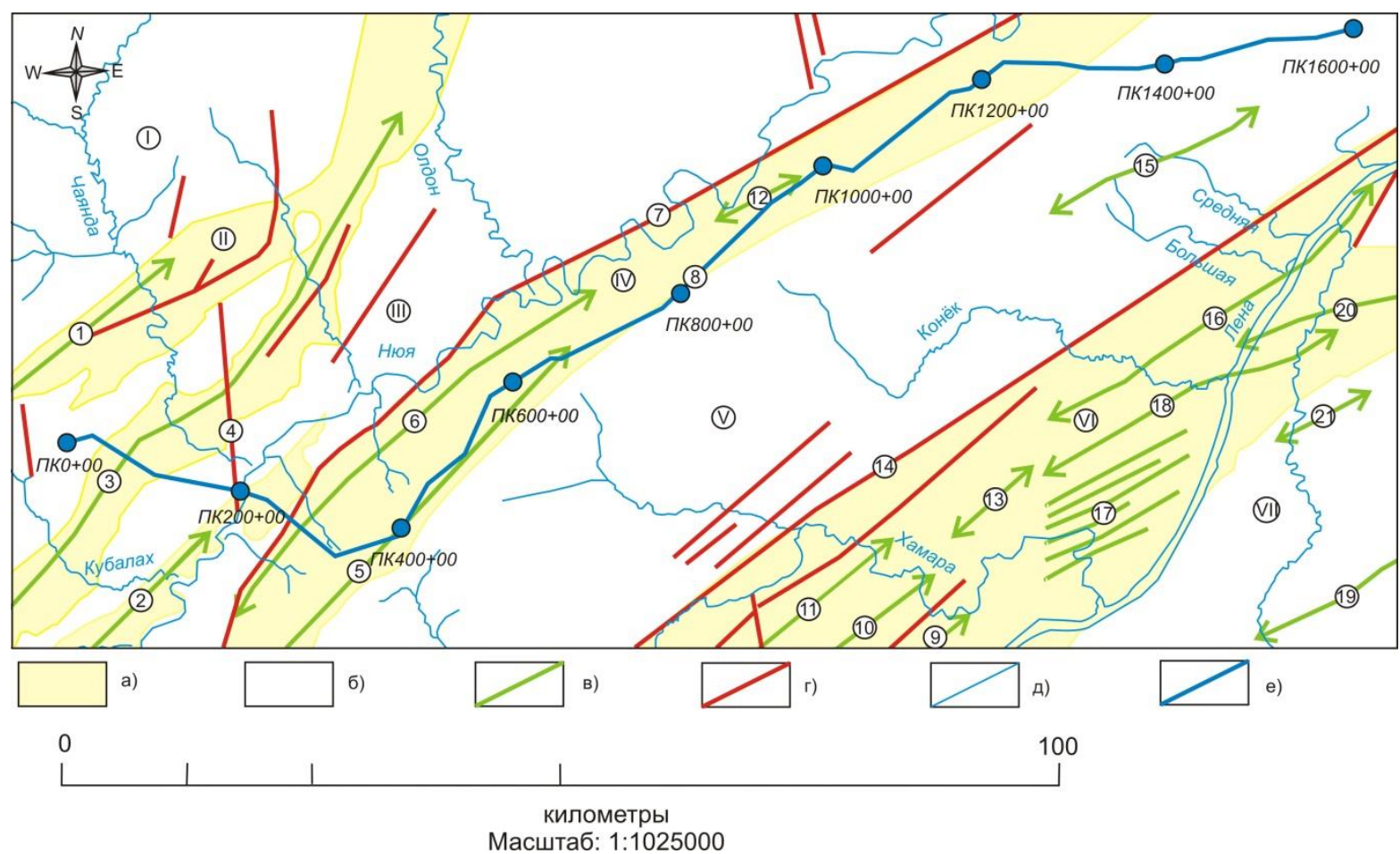

Рис. 2. Обзорная схема основных тектонических зон (А.В. Ежкова, 2018): а) антиклинальные зоны; б) синклинальные зоны; в) оси складок; г) разломы; д) гидросеть; е) трасса газопровода. I- Верхнечаяндинская зона пологих дислокачий; II - Пеледуй-Олдонская антиклинальная зона; III - Нюйская синклинальная зона; IV - Средненюйская антиклинальная зона; V-Нюйско-Хамаринская синклинальная зона; VI - Мухтуйская антиклинальная зона; VII - Витимо-Джербинская синклинальная зона. 1 - Кубалахская антиклиналь; 2 - Чаяндинская антиклиналь; 3 - Сюльджюкярская антиклиналь; 4 - Чаяндинский сброс; 5 - Ульяновская антиклиналь; 6 - Тас-Уряхская антиклиналь; 7 - Нюйский взброс; 8 - Южно-Нюйский разлом; 9 - Хамаринская антиклиналь; 10 - Тарын-Юряхская антиклиналь; 11 - Иниэхская антиклиналь; 12 - Нюйская антиклиналь; 13 - Доргоннохская антиклиналь; 14 - Хамаринский разлом; 15 - Нюйская синклиналь; 16 - Терешкинская антиклиналь; 17 - Хамринские линейные складки; 18 - Коньковская антиклиналь; 19 - Витимо-Джербинская синклиналь; 20 - Южно-Мухтуйская антиклиналь; 21 - Халамандинская антиклиналь

Fig. 2. Overview of the main tectonic zones (A.V. Ezhkova, 2018): a) anticlines; б) synclines; в) fold axes; г) faults; e) hydro grid; d) gas pipeline route. I - Verkhnechayandinskaya area of shallow dislocations; II - Peleduy-Oldonskaya anticlinal zone; III - Nyuyskaya synclinal area; IV - Srednenyuyskaya anticlinal zone; V - Nyuysko-Khamarinskaya synclinal area; VI - Mukhtuyskaya anticlinal zone; VII - Vitimo-Dzherbinskaya synclinal area. 1 - Kubalakhskaya anticline; 2 - Chayandinskaya anticline; 3 - Syuldzhyukyarskaya anticline; 4 - Chayandinskiy fault; 5 - Ulyanovskaya anticline; 6 - Tas-Uryakhskaya anticline; 7 - Nyuyskiy uplift; 8 - Yuzhno-Nyuyskiy fault; 9 - Khamarinskaya anticline; 10 - Taryn-Yuryakhskaya anticline; 11 - Iniyekhskaya anticline; 12 - Nyuyskaya anticline; 13 Dorgonnokhskaya anticline; 14 - Khamarinskiy fault; 15 - Nyuyskaya synclinal fold; 16 - Tereshkinskaya anticline; 17 - Khamrinskie linear folds; 18 - Konkovskaya anticline; 19 - Vitimo-Dzherbinskaya synclinal fold; 20 - YuzhnoMukhtuyskaya anticline; 21 - Khalamandinskaya anticline 
Общим признаком антиклинальных структур Пеледуй-Олдонской зоны является их большая протяженность при незначительной амплитуде поднятия. На двух участках трасса газопровода расположена в пределах Нюйской синклинальной зоны, которая является одной из крупных структур НюйскоДжербинской впадины. Отложения среднеговерхнего кембрия и нижнего ордовика в центральной части структуры залегают практически горизонтально Углы наклона слоев не превышают $20^{\circ}$. В пределах Нюйской синклинальной зоны трасса газопровода пересекает Чаяндинский сброс. Большая часть трассы газопровода расположена в пределах Средненюйской антиклинальной зоны. Средненюйская антиклинальная зона шириной 20-30 км занимает водораздельное пространство между Пеледуем и Нюей, Хамрой и Нюей и представляет собою полосу валообразных, иногда гребневидных, ундулирующих и кулисообразно расположенных антиклинальных складок, сопряженных с такими же или более широкими и пологими синклиналями. Учитывая широкое распространение разрывных и иных нарушений на изучаемой территории, можно сделать вывод о том, что структурнотектонические условия исследуемой территории способствуют развитию карста.

Инженерно-геологические особенности территории в значительной мере определяются коренными породами как непосредственно, так и через состав и свойства продуктов их выветривания. В пределах полосы газопровода распространены осадочные формации, среди которых выделяются: 1) карбонатная нижнекембрийская и среднекембрийская; 2) терригенно-карбонатная средне-верхнекембрийская, нижнеордовикская и средне-верхнеордовикская; 3) терригенная нижнеюрская. В целом геологическое строение территории благоприятно для развития карстового процесса, учитывая широкое распространение карбонатных пород, наличие трещин. В областях развития карбонатных пород нижнепалеозойского возраста распространены карстовые формы. Развитию карста может способствовать глубокое расчленение территории и трещиноватость пород. По трещинам происходит активная циркуляция подземных вод, и как следствие - растворение и вынос относительно легко растворимых минералов. Карст на поверхности проявляется в виде воронок, полостей, понор и карстовых рвов.

Непосредственно в пределах полосы отвода магистрального газопровода «Сила Сибири» участок «Чаянда-Ленск» был зафиксирован ряд карстопроявлений. Наиболее распространены локальные понижения земной поверхности - блюдца. Глубина данных понижений варьируется в пределах 0,5-3,32 м, диаметр составляет 23-63 м. Карстующиеся породы представлены преимущественно доломитами, встречаются известняки. Заполняющие породы выполнены суглинками, супесями, щебнем. Пораженность территории составляет менее $5 \%$, процесс карстообразования относится к умеренно опасным. В то же время данная характеристика не отражает реальную опасность процесса на отдельных участках трассы трубопровода
Согласно действующим нормативным документам при производстве изысканий в карстовых районах в труднорастворимых карбонатных породах основное внимание должно быть направлено на выявление уже сформировавшихся карстовых форм (их положения и параметров), поскольку время, необходимое для образования новых значительных по размеру карстовых пустот, несоизмеримо, как правило, со сроком службы инженерных сооружений. Зафиксированные непосредственно в полосе отвода поверхностные проявления карста - блюдца, представляют наименьшую опасность для трубопровода ввиду значительного удаления от оси трассы и отсутствия сложностей их идентификации на этапе изысканий. Наибольшую опасность представляют подземные формы, в том числе не в полной мере реализованные, идентификация и определение параметров которых зачастую представляют значительные сложности.

\section{Исходные данные и методы исследования}

В качестве исходных данных для проведения исследования использовались материалы комплексных инженерных изысканий территории, проведенных ООО «Ингеоком», ООО «Промнефтегазпроект», ФГУП «ВостСибАГП» по объекту «Магистральный газопровод "Сила Сибири"», участок «Чаянда-Ленск». Фактический материал по скважинам составил 763 скважины, были проанализированы данные по 85 инженерно-геологическим элементам. В ходе проведения комплексных инженерных изысканий при проходке скважин были зафиксированы провалы бурового инструмента, связанные, предположительно, с наличием пустот и разуплотненных зон в массиве карстующихся пород по трассе газопровода. В связи с большим расстоянием между скважинами (200-300 м) в работе использованы результаты электроразведки БЭЗ для определения зоны предполагаемого карстового образования. В результате анализа было предварительно выделено 23 участка, характеризующихся неоднородностью массива карстующихся пород по геолого-геофизическим данным. Таким образом, в качестве показателя закарстованности была выбрана неоднородность массива карстующихся пород (известняков и доломитов), которая может быть выражена через соответствующий коэффициент - «коэффициент неоднородности массива карстующихся nород». Вся трасса трубопровода протяженностью 160 км была условно разделена на равные отрезки по 500 м. На каждом отрезке рассчитывался коэффициент, равный отношению протяженности зоны предполагаемого развития карстового процесса к длине отрезка. Первоначальный объем выборки составил 320 позиций (отрезков). При дальнейшем анализе было выделено 59 отрезков, обладающих наибольшей информативностью (исключены участки размещения трассы в зоне юрских некарстующихся отложений, а также участки, характеризующиеся однородностью массива по геофизическим данным и данным бурения). Вся выборка была разделена на подвыборки по геоморфологическому признаку. 
Для выделения зон повышенной трещиноватости по данным дистанционного зондирования в дальнейшем проведен линеаментный анализ. Главным условием возможности его использования является отражение геологических особенностей строения территории в рельефе. Геологические признаки линеаментов представляют собой выходы на земную поверхность разрывных нарушений. Среди геоморфологических индикаторов линеаментов на данной территории следует назвать линейно-вытянутые спрямленные денудационные уступы на склонах долин и водоразделов; прямолинейные бровки и вогнутые перегибы на склонах, ограничивающие участки с различной крутизной; центральные части седловин на водоразделах и др. Эти геоиндикационные признаки наиболее отчётливо проявлены на участках с увеличенной расчленённостью рельефа. Эрозионные формы рельефа проявляются в виде прямолинейных отрезков русел, тальвегов ложков и ложбин стока, тыловых швов и бортов речных долин; резких коленообразных изгибов временных и постоянных водотоков.
Для анализа линеаментов использовались мозаика трех сцен (рис. 3), полученных при помощи космического термоэмиссионного и отражающего радиометpa ASTER, отраженных в GDEM (Global Digital Elevation Model). ЦРМ в растровом формате представляет собой регулярную сетку абсолютных отметок рельефа, которая может быть визуализирована в оттенках серого цвета. Эта ЦМР выбрана потому, что имеет детальное пространственное разрешение (25 м) в сочетании с точностью по высоте и однородности исходного материала и минимальным количеством пустот.

Непосредственно для выделения линеаментов использовалась программа ГИС Geomatica (PCI Geomatics, Канада). Использование данного программного продукта выбрано в связи с его доступностью, широкими возможностями обработки векторных и растровых данных, представленных в более чем 100 различных форматах, простотой автоматизации процессов обработки информации.

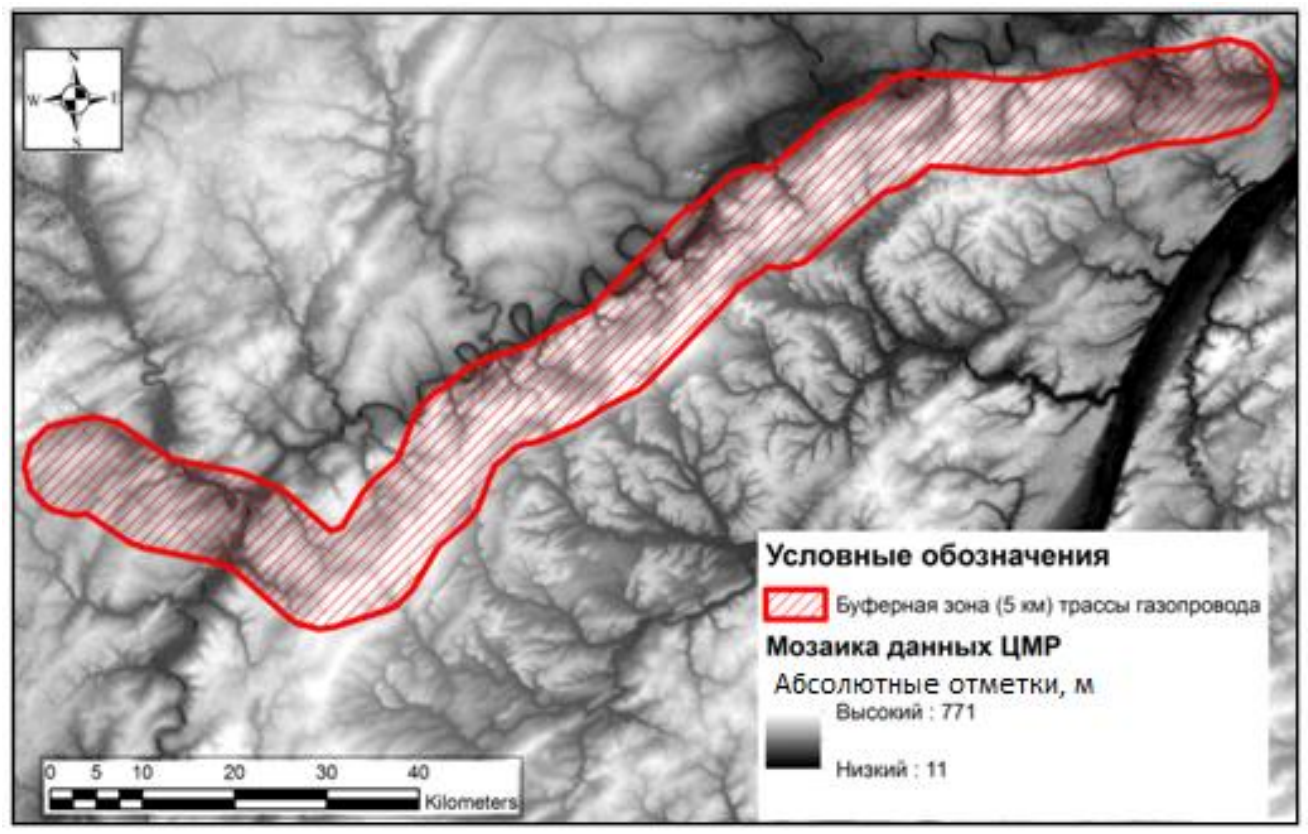

Puc. 3. Мозаика трех сиен «ASTER Gdem» 28

Fig. 3. Mosaic of three scenes «ASTER Gdem» 28

Для идентификации линеаментов в автоматизированном режиме использовался инструмент LINE: Lineament Extraction. Алгоритм работы модуля включает три основных этапа: идентификация границ, пороговая обработка, извлечение границ. На первом этапе при помощи алгоритма обнаружения границ Кэнни (Canny edge detector) выделялись линейно ориентированные элементы, представляющие собой цепь вытянутых в пространстве пикселей растра, близких по значениям абсолютных высот и резко выделяющихся среди окружающих. На втором этапе линейно ориентированные линии пикселей растра, выделяющиеся по абсолютным высотам среди окружающих, конвертировались в однобитный (черно-белый) растр (чер- ный цвет - линеаменты, белый - остальные пиксели). На третьем этапе однобитный растр конвертируется в линейный векторный слой, отражающий линейноориентированные элементы (рис. 4).

Суммарные длины (в км) штрихов разных направлений образуют следующий ряд по мере уменьшения величины длины: $45^{\circ}, 315^{\circ}, 0^{\circ}, 22^{\circ}, 90^{\circ}, 67^{\circ}, 293^{\circ}$, $338^{\circ}$, т. е. наиболее распространена диагональная система штрихов.

Густота (плотность) расположения данных линейно-ориентированных элементов соответствует расчлененности ландшафта дневной поверхности на исследуемой территории. Картосхема линейной плотности линеаментов приведена на рис. 5. 


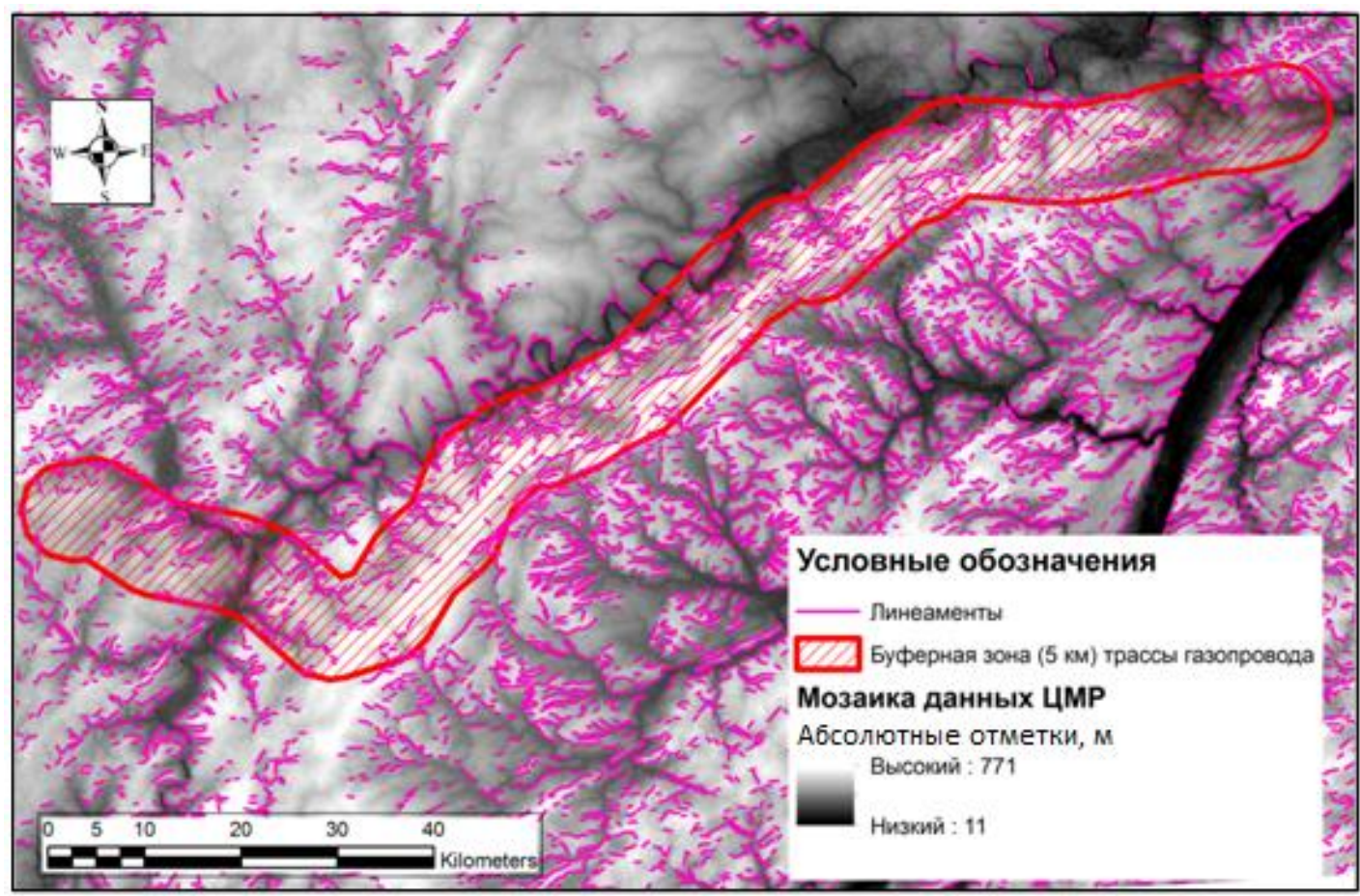

Pис. 4. Линеаменты, выделенные по LMP «ASTER Gdem V03»

Fig. 4. Lineaments selected by the DEM «ASTER Gdem V03»

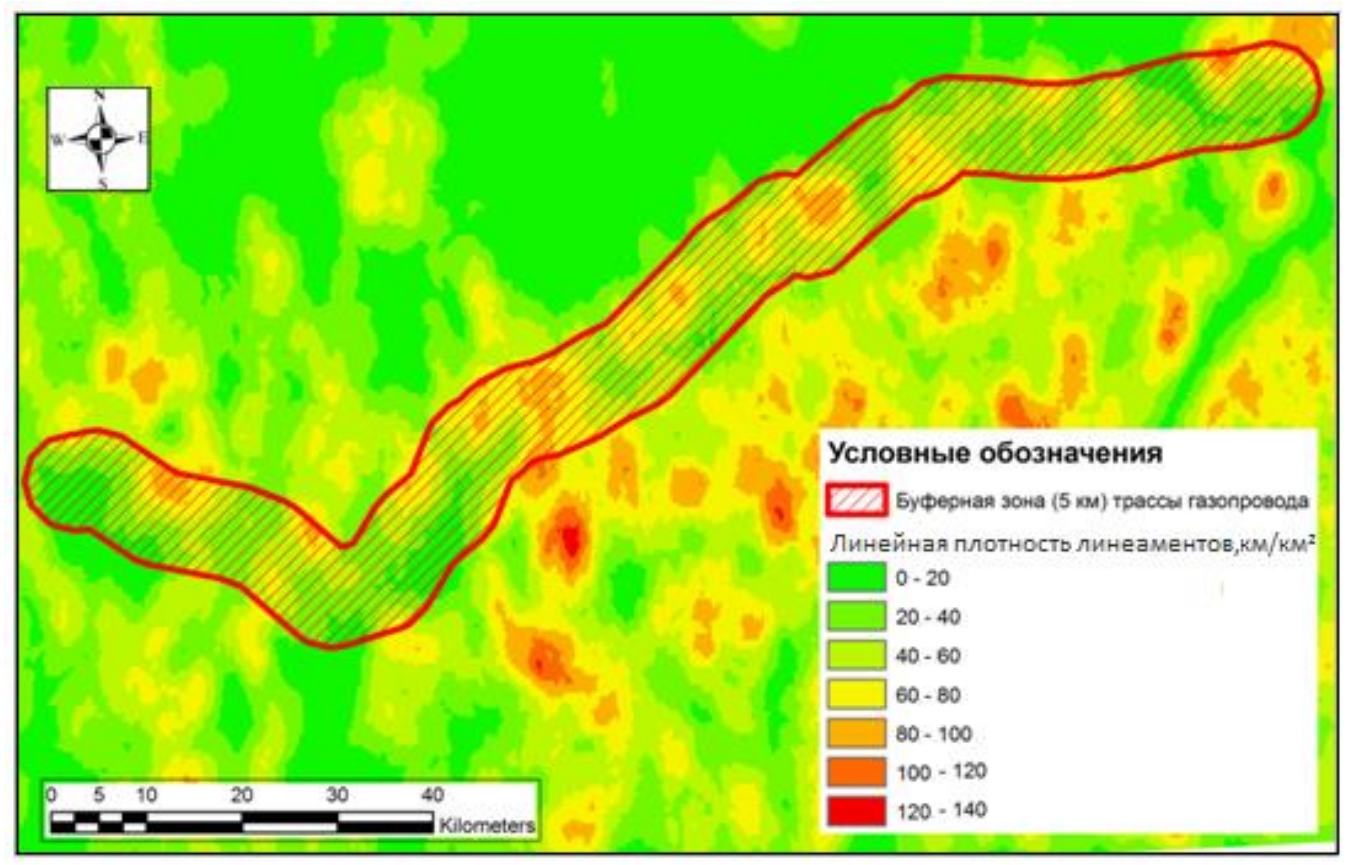

Рис. 5. Картосхема плотности линеаментов

Fig. 5. Map of lineaments density

\section{Результаты}

При наложении карты плотности линеаментов и тектонической схемы прослеживается, что локальные линейно-вытянутые области аномальной плотности линеаментов приурочены к зонам разломов северозападного простирания. Необходимо отметить, что подавляющее большинство глубинных разломов, выделенных геолого-геофизическими методами, прояв- ляются на космических снимках линеаментами, пространственно совпадая с их осевыми линиями или трассируясь параллельно им в непосредственной близости.

Наложение картосхемы плотности линеаментов и картосхемы потенциально опасных участков проявлений карста (рис. 6) показало связь между этими параметрами (таблица), о чем неоднократно указывалось и другими исследованиями $[1,4,5,21]$. 


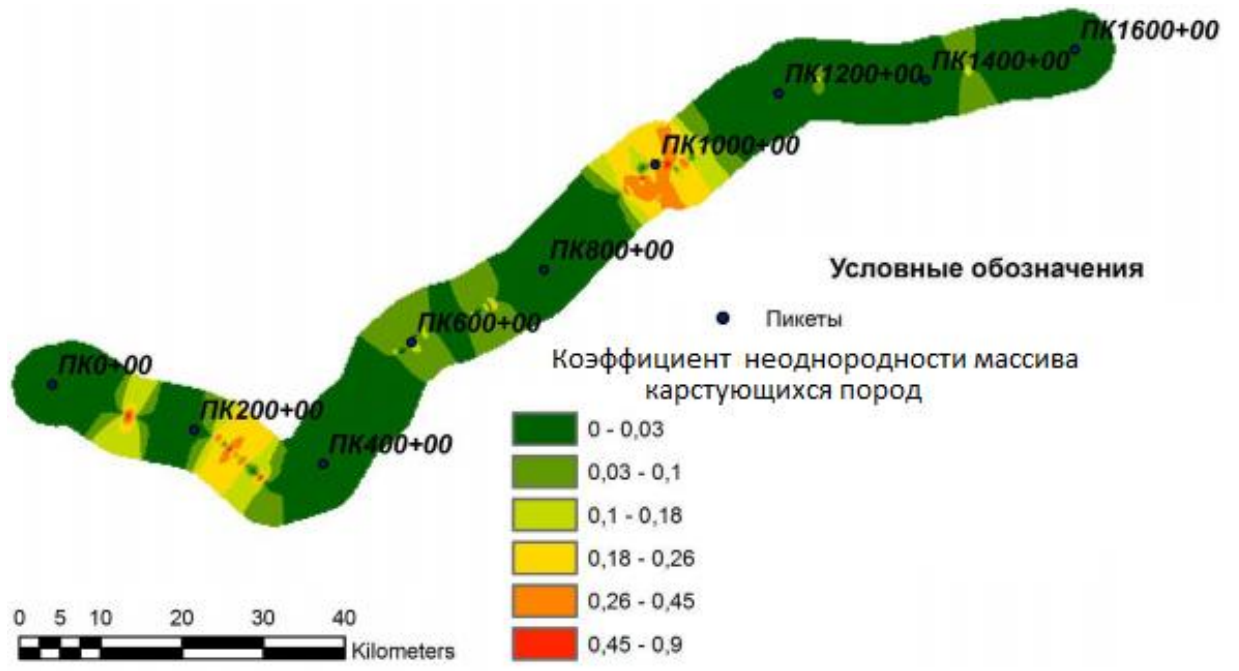

Рис. 6. Картосхема потенциально опасных участков проявлений карста

Fig. 6. Map of potentially dangerous areas of karst manifestations

Таблица. Коэффициенты корреляции между закарстованностью и линеаментами

Table. Correlation coefficients between the karst forms and lineaments

\begin{tabular}{|c|c|c|}
\hline \multirow{2}{*}{$\begin{array}{l}\text { Наименование выборки } \\
\text { Name of the sample }\end{array}$} & \multicolumn{2}{|c|}{$\begin{array}{c}\text { Коэффициенты корреляции между закарстованностью и линеаментами } \\
\text { Correlation coefficients between the karst forms and lineaments }\end{array}$} \\
\hline & $\begin{array}{c}\text { Линейная плотность линеаментов, км/км² } \\
\text { Linear density of lineaments, } \mathrm{km} / \mathrm{km}^{2} \\
\end{array}$ & $\begin{array}{c}\text { Удаленность от линеаментов, м } \\
\text { Distance from lineaments, } \mathrm{m}\end{array}$ \\
\hline Весь участок/Entire section & 0,726 & $-0,704$ \\
\hline $\begin{array}{l}\text { Надпойменная терраса } \\
\text { Above-floodplain terrace }\end{array}$ & 0,750 & $-0,689$ \\
\hline $\begin{array}{l}\text { Подножия склонов } \\
\text { Foot of the slopes }\end{array}$ & 0,902 & $-0,744$ \\
\hline $\begin{array}{l}\text { Поверхности выравнивания } \\
\text { Alignment surfaces }\end{array}$ & 0,537 & $-0,871$ \\
\hline
\end{tabular}

Согласно представленным результатам были получены достаточно высокие коэффициенты корреляции, что свидетельствует о взаимосвязи между развитием подземных карстопроявлений и наличием линеаментов. В результате проведенных расчетов можно сделать вывод о том, что наиболее предрасположены к возможной активизации карстового процесса в целом по трассе газопровода участки, приуроченные к зонам повышенной трещиноватости массива.

Наши результаты показали неравнозначность выделения линеаментов в различных частях рельефа, например, для водоразделов и речных долин, поэтому этот вопрос требует проведения дальнейших исследований и подтверждения на других участках.

\section{Заключение}

Широкое распространение разрывных и иных нарушений на изучаемой территории позволяет сде-

\section{СПИСОК ЛИТЕРАТУРЬ}

1. Печеркин А.И., Болотов Г.Б., Катаев В.Н. Изучение тектонической трещиноватости платформенных структур для карстологических целей. Учебное пособие по спецкурсу. - Пермь: Пермский университет, 1984. - 85 с.

2. Катаев В.Н. Основы структурного картоведения. - Пермь: Пермский ун-т, 2004. - 109 с.

3. Чернов И.Ю., Нугманов И.И., Кадыров Р.И. Автоматизированный линеаментный анализ. - Казань: Казанский (Приволжский) федеральный университет, 2012. - 38 с. лать вывод о том, что структурно-тектонические условия исследуемой территории способствуют развитию карста.

Анализ публикаций, обработка данных цифровой модели рельефа, полученных из открытых источников, позволили составить схему распространения линеаментов и схему плотности линеаментов, с указанием зон повышенной трещиноватости и, как следствие, более активным карстообразованием.

Полученные результаты наряду с другими факторами использовались для оценки карстовой опасности района трассы магистрального газопровода в южной Якутии.

Исследование выполнено в Томском политехническом университете в рамках программы повышения конкурентоспособности Томского политехнического университета (средства ВИУ).

4. Золотарев Д.Р., Катаев В.Н. Воздействие линеаментной тектоники на развитие карстовых процессов на локальном уровне // ГЕОРИСК - 2013 - № 1. - С. 34-43.

5. Влияние геологического строения территории на распределение карстовых форм (на примере территории г. Кунгура) / В.Н. Катаев, С.В. Щербаков, Д.С. Золотарев, О.М. Лихая, Т.Г. Ковалева // Вестник Пермского университета. Научный журнал. Вып. 3 Геология. - 2009. - Вып. 4. - № 33. - С. 77-93.

6. Щербаков С.В., Катаев В.Н. Интегральная оценка карстоопасности урбанизированных территорий (на примере г. Кунгур) // Ученые записки Казанского университета. Серия: Естественные науки. - 2011. - Т. 153. - Кн. 1. - С. 203-224. 
7. Ruiz-Fernández J., Oliva M., Hughes P. Permafrost and periglacial processes in mid- and low-latitude mountain regions // Permafrost and Periglacial Processes. - 2019. - V. 30. - № 4. - P. 245-248.

8. Computer vision-based framework for extracting tectonic lineaments from optical remote sensing data / E. Farahbakhsh, R. Chandra, H.K.H. Olierook, R. Scalzo, C. Clark, S.M. Reddy, R.D. Müller // International Journal of Remote Sensing. - 2020. V. 41. - № 5. - P. 1760-1787. DOI: 10.1080/01431161.2019.1674462

9. Structural analysis and Miocene-to-Present tectonic evolution of a lithospheric-scale, transcurrent lineament: the Sciacca Fault (Sicilian Channel, Central Mediterranean Sea) / J. Fedorik, G. Toscani, E. Lodolo, D. Civile, L. Bonini, S. Seno // Tectonophysics. - 2018. - V. 722. - P. 342-355. URL: https://doi.org/10.1016/j.tecto.2017.11.014 (дата обращения 10.06.2020).

10. Tectonics of the Northeastern border of the Parana Basin (Southeastern Brazil) revealed by lineament domain analysis / M.R. Pinheiro, P. Cianfarra, F.N.J. Villela, F. Salvini // Journal of South American Earth Sciences. - 2019. - V. 94. - № 102231. URL: https://doi.org/10.1016/j.jsames.2019.102231 (дата обращения 10.06.2020)

11. Prabhakaran A., Raj N.J. Mapping and analysis of tectonic lineaments of Pachamalai hills, Tamil Nadu, India using geospatial technology // Geology, Ecology, and Landscapes. - 2018. - V. 2. № 2. - P. 81-103. DOI: 10.1080/24749508.2018.145248

12. Fracture mapping of lineaments and recognizing their tectonic significance using SPOT-5 satellite data: a case study from the Bajestan area, Lut Block, east of Iran / R. Ahmadirouhani, B. Rahimi, M.H. Karimpour, A.M. Shafaroudi, S.A. Najaf, A.B. Pour // Journal of African Earth Sciences. - 2017. - V. 134. P. 600-612. URL: https://doi.org/10.1016/j.jafrearsci.2017.07.027 (дата обращения 10.06.2020).

13. Das S., Pardeshi S.D. Comparative analysis of lineaments extracted from Cartosat, SRTM and ASTER DEM: a study based on four watersheds in Konkan region, India // Spatial Information Research. - 2018. - V. 26. - № 1. - P. 47-57. URL https://doi.org/10.1007/s41324-017-0155-х (дата обращения 10.06.2020).
14. Extraction of lineaments from different azimuth angles using geospatial techniques: a case study of Pravara basin, Maharashtra, India / S. Das, S.D. Pardeshi, P.P. Kulkarni et al. // Arabian Journal of Geosciences. - 2018. - V. 11. - № 160. URL: https://doi.org/10.1007/s12517-018-3522-6 (дата обращения 10.06.2020)

15. Технический отчет. Выполнение комплексных инженерных изысканий по объекту «Магистральный газопровод «Сила Сибири». Участок Чаянда-Ленск. В 5 т. - Саратов: ОАО «ВНИПИгаздобыча», 2012. - Т. 2. - 2886 с.

16. Строкова Л.А., Ермолаева А.В. Районирование территории по степени опасности оседания земной поверхности при проектировании магистрального газопровода в южной Якутии // Известия Томского политехнического университета. Инжиниринг георесурсов. - 2016. - Т. 327. - № 10. - С. 59-68.

17. Строкова Л.А., Епифанова Е.А., Коржнева Т.Г. Численный анализ поведения основания опоры моста на старой железнодорожной линии // Известия Томского политехнического университета. Инжиниринг георесурсов. - 2017. - Т. 328. - № 5. C. $125-139$.

18. Purgina D.V., Strokova L.A., Kuzevanov K.I. Modeling of changing hydrogeological conditions during construction of pier foundations on the Kama river bank // IOP Conference Series: Earth and Environmental Science. - 2016. - V. 33. - 6 p. http://iopscience.iop.org/article/10.1088/1755-1315/33/1/012046

19. Strokova L.A. Recognition of geological processes in permafrost conditions // Bulletin of Engineering Geology and the Environment. - 2019. - V. 78. - № 8. - P. 5517-5530. URL: https://doi.org/10.1007/s10064-019-01511-4 (дата обращения 10.06.2020).

20. Строкова Л.А., Ермолаева А.В. Природные особенности строительства участка газопровода «Сила Сибири» на участке Чаяндинское нефтегазоконденсатное месторождение - Ленск // Известия Томского политехнического университета. - 2015. Т. 326. - № 4. - C. 41-55.

21. Кац Я.Г., Полетаева А.И., Румянцева Э.Ф. Основы линеаментной тектоники. - М.: Недра, 1986. - 140 c.

Поступила 29.06.2020 2.

\section{Информация об авторах}

Строкова Л.А., доктор геолого-минералогических наук, профессор отделения геологии Инженерной школы природных ресурсов Национального исследовательского Томского политехнического университета.

Ежккова А.В., инженер, ООО «Газпром Инвест».

Леонова A.B., старший преподаватель отделения геологии Инженерной школы природных ресурсов Национального исследовательского Томского политехнического университета. 
UDK 624.131

\title{
APPLICATION OF LINEAMENT ANALYSIS TO ASSESS THE KARST HAZARD IN THE DESIGN OF THE MAIN GAS PIPELINE IN SOUTH YAKUTIA
}

Lyudmila A. Strokova ${ }^{1}$, sla@tpu.ru

\author{
Alena V. Ezhkova², \\ alyona7@inbox.ru \\ Anna V. Leonova', \\ avleonova@tpu.ru \\ 1 National Research Tomsk Polytechnic University, \\ 30, Lenin avenue, Tomsk, 634050, Russia. \\ 2 Gazprom Invest, \\ 39, Lenin avenue, Tomsk, 634034, Russia.
}

Relevance of the work is caused by construction of the main gas pipeline in southern Yakutia. The area is characterized by complex natural and climatic conditions, poor geological engineering study, and extensive development of karst rocks. Taking into consideration the insufficiency of karst observation data, lineament analysis of satellite images has great importance for studying rock fracture zones. A lineament on a satellite image is a linear-banded image texture that reflects the features of the geological structure on the ground, such as zones of discontinuities, cracks and rock crushing, which are associated with the maximum permeability of the earth's crust for heat and mass transfer and migration of gas and liquid solutions. The latter circumstance opens the way to assess and forecast not only the prospects of the territory for the presence of natural resource, but also the danger of the development of exogenous geological processes, such as linear erosion, karst, landslides. The physical nature of the relationship between lineaments and karst manifestations allows us to use lineament analysis in assessing the conditions of construction of structures on karst territories.

The main aim of the study is to understand the spatial distribution of lineaments, their orientation, density, as a factor affecting the development of the karst process.

Methods. The main focus of the study is on extraction of lineaments within the route of the main gas pipeline, using a digital terrain model. The lineaments were extracted and analyzed in the Geomatica and ArcGIS programs, respectively.

Results. The use of modern technologies for selecting lineaments on satellite images opens up new opportunities for studying the geological structure of the territory. Maps of distribution of lineaments and their density in the studied area are made. Information on the structural and tectonic conditions of the territory and the obtained results of lineament analysis were used to assess the karst hazard of the route area.

\section{Key words:}

Main gas pipelines, risk assessment, lineament, geoinformation systems, karst

The research was carried out at Tomsk Polytechnic University within the Program of Tomsk Polytechnic University Competitiveness Enhancement (VIU funds).

\section{REFERENCES}

1. Pecherkin A.I., Bolotov G.B., Kataev V.N. Izuchenie tektonicheskoy treshchinovatosti platformennykh struktur dlya karstologicheskikh tseley [Study of tectonic fracturing of platform structures for karstological purposes]. Perm, Perm University Publ., 1984. 85 p.

2. Kataev V.N. Osnovy strukturnogo kartovedeniva [Fundamentals of structural karst studies]. Perm, Perm University Publ., 2004. 109 p.

3. Chernov I.Yu., Nugmanov I.I., Kadyrov R.I. Avtomatizirovanny lineamentny analiz [Automated lineament analysis]. Kazan, Kazan Federal University Publ., 2012. 38 p.

4. Zolotarev D.R., Kataev V.N. Lineament tectonic influence on development of karst processes at the local level. Georisk, 2013, no. 1, pp. 34-43. In Rus.

5. Kataev V.N., Shherbakov S.V., Zolotarev D.S., Lihaja O.M., Kovaleva T.G. Influence of the geological structure of the territory on the distribution of karst forms (on the example of the territory of Kungur. Bulletin of Perm University. Geology, 2009, vol. 4, no. 33, pp. 77-93. In Rus.

6. Shherbakov S.V. Kataev V.N. Integral estimation of karst hazard of urbanized territories (on the example of Kungur). Uchenye Zapiski Kazanskogo Universiteta. Seriya Estestvennye Nauki, 2011, vol. 153, no. 1, pp. 203-224. In Rus.

7. Ruiz-Fernández J., Oliva M., Hughes P. Permafrost and periglacial processes in mid- and low-latitude mountain regions. Permafrost and Periglacial Processes, 2019, vol. 30, no. 4, pp. 245-248.
8. Farahbakhsh E., Chandra R., Olierook H.K.H., Scalzo R., Clark C., Reddy S.M., Müller R.D. Computer vision-based framework for extracting tectonic lineaments from optical remote sensing data, International Journal of Remote Sensing, 2020, vol. 41, no. 5, pp. 1760-1787. DOI: 10.1080/01431161.2019.1674462

9. Fedorik J., Toscani G., Lodolo E., Civile D., Bonini L., Seno S. Structural analysis and Miocene-to-Present tectonic evolution of a lithospheric-scale, transcurrent lineament: the Sciacca Fault (Sicilian Channel, Central Mediterranean Sea). Tectonophysics, 2018, vol. 722, pp. 342-355. Available at: https://doi.org/10.1016/ j.tecto.2017.11.014 (accessed 10 June 2020).

10. Pinheiro M.R., Cianfarra P., Villela F.N.J., Salvini F. Tectonics of the Northeastern border of the Parana Basin (Southeastern Brazil) revealed by lineament domain analysis. Journal of South American Earth Sciences, 2019, vol. 94, 102231. Available at: https:/l doi.org/10.1016/j.jsames.2019.102231 (accessed 10 June 2020).

11. Prabhakaran A., Raj N.J. Mapping and analysis of tectonic lineaments of Pachamalai hills, Tamil Nadu, India using geospatial technology. Geology, Ecology, and Landscapes, 2018, vol. 2, no. 2, pp. 81-103. DOI: 10.1080/24749508.2018.1452481

12. Ahmadirouhani R., Rahimi B., Karimpour M.H., Shafaroudi A.M., Najaf S.A., Pour A.B. Fracture mapping of lineaments and recognizing their tectonic significance using SPOT-5 satellite data: a case study from the Bajestan area, Lut Block, east of Iran. Journal of African Earth Sci- 
ences, 2017, vol. 134, pp. 600-612. Available at: https://doi.org/ 10.1016/j.jafrearsci.2017.07.027 (accessed 10 June 2020)

13. Das S., Pardeshi S.D. Comparative analysis of lineaments extracted from Cartosat, SRTM and ASTER DEM: a study based on four watersheds in Konkan region, India. Spatial Information Research, 2018, vol. 26, no. 1, pp. 47-57. Available at: https:// doi.org/ 10.1007/s41324-017-0155-x (accessed 10 June 2020).

14. Das S., Pardeshi S.D., Kulkarni P.P. Extraction of lineaments from different azimuth angles using geospatial techniques: a case study of Pravara basin, Maharashtra, India. Arabian Journal of Geosciences, 2018, vol. 11, no. 160. Available at: https://doi.org/ 10.1007/s12517-018-3522-6 (accessed 10 June 2020).

15. Tekhnicheskiy otchet. Vypolnenie kompleksnykh inzhenernykh izyskaniy po obektu «Magistralny gazoprovod "Sila Sibiri"». Uchastok Chayanda-Lensk [Technical report. Performing complex engineering surveys for the Power of Siberia gas Main pipeline project. Chayanda-Lensk Section]. Saratov, OAO «VNIPIgazdobycha», 2012. Vol. 2, 2886 p.

16. Strokova L.A., Ermolaeva A.V. Zoning according to the hazard level of earth surface subsidence when designing the main gas pipeline in south Yakutia. Bulletin of the Tomsk Polytechnic University. Geo Assets Engineering, 2016, vol. 327, no. 10, pp. 59-68. In Rus.
17. Strokova L.A., Epifanova E.A., Korzhneva T.G. Numerical analysis of bridge foundation behaviour on the old railway line. Bulletin of the Tomsk Polytechnic University. Geo Assets Engineering, 2017, vol. 328, no. 5, pp. 125-139. In Rus.

18. Purgina D.V., Strokova L.A., Kuzevanov K.I. Modeling of changing hydrogeological conditions during construction of pier foundations on the Kama river bank. IOP Conference Series: Earth and Environmental Science, 2016,33, 012046. http://iopscience.iop.org/article/10.1088/1755-1315/33/1/012046

19. Strokova L.A., Recognition of geological processes in permafrost conditions. Bulletin of Engineering Geology and the Environment, 2019, vol. 78, no. 8, pp. 5517-5530. Available at: https:// doi.org/10.1007/s10064-019-01511-4 (accessed 10 June 2020).

20. Strokova L.A., Ermolaeva A.V. Natural features of construction of the main gas pipeline "The Power of Siberia» on a site Chayandinskoye oil and gas field - Lensk. Bulletin of the Tomsk Polytechnic University, 2015, vol. 326, no. 4, pp. 41-55. In Rus.

21. Katz Ya.G., Poletaeva A.I., Rumyantseva E.F. Osnovy lineamentnoy tektoniki [Fundamentals of lineament tectonics]. Moscow, Nedra Publ., 1986. 140 p.

Received: 29 June 2020.

\section{Information about the authors}

Lyudmila A. Strokova, Dr. Sc., professor, National Research Tomsk Polytechnic University.

Alena V. Ezhkova, engeneer, Gazprom Invest.

Anna V. Leonova, senior lecturer, National Research Tomsk Polytechnic University. 